\title{
3 Researc Square

\section{Differences in Functionality Between Independent, Slight, and Moderate Dependent Older Adults: A Cross-sectional Study}

María Teresa Valenzuela ( $\nabla$ mtvalenzuela@uandes.cl )

Universidad de los Andes

Claudia Rodriguez

CIEF. Universidad de los Andes

Diego González

CIEF. Universidad de los Andes

Andres Glasinovic

CIEF. Universidad de los Andes

Rodrigo Guzmán-Venegas

CIEF. Universidad de los Andes

Ignacio Perez

CIEF. Universidad de los Andes

María del Pilar Ureta

Universidad de los Andes

Yasha Feferholtz

Universidad de los Andes

Pamela San Martín

Universidad de los Andes

\section{Research Article}

Keywords: Older adults, functional capacity, cognitive capacity, quality of life, multidimensional intervention. Barthel Index, EQ-5D, health status, depression

Posted Date: April 9th, 2021

DOl: https://doi.org/10.21203/rs.3.rs-322457/v1

License: (c) (1) This work is licensed under a Creative Commons Attribution 4.0 International License.

Read Full License 
1 Differences in functionality between independent, slight, and moderate dependent

2 older adults: a cross-sectional study

3

4 María Teresa Valenzuela ${ }^{1}$, Claudia Rodriguez², Diego González ${ }^{3}$, Andres Glasinovic ${ }^{4}$,

5 Rodrigo Guzmán-Venegas ${ }^{3}$, Ignacio Perez ${ }^{5}$, María del Pilar Ureta $^{6}$, Yasha Feferholtz ${ }^{7}$,

6 Pamela San Martín ${ }^{7}$

7

8

9

10 'Vice dean of Research Faculty of Medicine. Universidad de Los Andes, Chile. CIEF

11 Director, email: mtvalenzuela@uandes.cl

$12{ }^{2}$ Midwife CIEF. Universidad de los Andes, Chile

$13{ }^{3}$ Physical Therapy, CIEF. Universidad de los Andes, Chile

$14 \quad{ }^{4}$ Family Medicine, CIEF. Universidad de los Andes, Chile

$15{ }^{5}$ Internal Medicine Residency. Universidad de los Andes, Chile

$16{ }^{6}$ Nurse CIEF. Universidad de los Andes, Chile

$17{ }^{7}$ Research Unit CIEF. Universidad de los Andes, Chile 


\section{Abstract}

28 Background: Aging is a gradual process characterized by damage to the physiological

29 functions that frequently lead to dependence in the older adults of 60 years or older. We

30 hypothesize significant differences in mental and physical capacity between fully

31 independent older adults and slight to moderate dependent older adults.

32 Method: A cross-sectional analysis of 322 older adults of 60 years or more, with a Barthel

33 Index equal to or higher than 60, who attended day centers during August 2018 in Santiago-

34 Chile was used. Quality of life, physical ability, cognitive capacity, and symptoms of

35 depression of fully independent with slight to moderate dependent older adults are 36 compared.

37 Results: A higher proportion of older adults with complete independence have higher levels 38 of quality of life and mobility. Even a small reduction in independence has a significant 39 reduction in quality of life. An increase from a 60-90 score to a 91-99 score in the Barthel 40 Index rises 42\% [CI95\% 18-66] the EQ-5D score, this difference increases to 49\% [CI95\%

41 29-70] for full independence. Climbing stairs and incontinence in urination are the two main 42 activities related to having a lower independence level (lower than 100 Barthel Index score). 43 Ambulation and climbing stairs are the two main activities related with lower than the cutoff

44 levels of normality for quality of life (EQ5D) and physical condition (TUG). Finally, urine and 45 bowel incontinence, and lower levels of ambulation are the main activities related with 46 symptoms of depression (Yesavage score).

47 Conclusion: There were significant differences in health-related measures among different 48 levels of independent older adults. Understanding the potential causes of these differences 49 could help prioritize the focus of multidimensional programs on health and prevention with 50 the aim of prolonging older adults' state of independence and improving their quality of life. 
53 Key Words: Older adults, functional capacity, cognitive capacity, quality of life,

54 multidimensional intervention. Barthel Index, EQ-5D, health status, depression.

Introduction

57 Aging is a gradual, long-standing, heterogeneous process characterized by progressive and cumulative damage to physiological functions (1), leading to dependency in older adults. Loss of functional capacity of older adults is determined by the loss of intrinsic capacity, related to physical and mental capacity and external factors, such as environmental, poverty

61 and low education levels. Also, abilities are affected by factors related to each person's

62 lifestyle (e.g. sedentarism, nutrition) (2).

64 Globally, there were over 703 million older adults over 65 years old in 2019, with at least

$659.1-9.4 \%$ of them that live under extreme poverty (3). It is projected that there will be 1.5 66 billion older people by 2050 (4). This demographic change has been drastic due to the 67 increase in life expectancy and low global fertility rates. Chile has not been aliened to this 68 process, according to the 2017 census the population aged 60 and over reached $16.2 \%$ (5), 69 which in number of people means over 2.8 million older adults. It is estimated that $24 \%$ of 70 older adults have some degree of dependency, up to severe dependency, as they become 71 older $(76 \%$ or 2.1 million of those older adults in Chile, therefore, are considered 72 independent) and sixty seven percent of them are afraid of losing their independence (6).

73 This dependency is even more common for older adults belonging to lower socioeconomic 74 levels (7-9), considering that $67 \%$ of older adults in Chile are afraid of losing their 75 independence (6). 
77 Loss of functional capacity leads to dependency which is marked by the need for older adults

78 to use third parties to carry out the basic and instrumental activities of daily life (ADL), such

79 as walking or dressing (7). However, there is no knowledge about the most important

80 determinants and factors that relate with the loss of functionality in older adults.

82 As an initial process, 322 older adults were selected and measured on their dependency

83 levels using the Barthel Index along with sociodemographic background, health measures,

84 cognitive capacities, and physical capacities.

86 Herein we examine whether there are significant differences among three levels of

87 dependency (moderate dependency, slight dependency, and independence; measured with

88 the Barthel Index $\left.((10))^{1}\right)$ in older adults who attend these day centers, and whether

89 anthropometric measures, health status, physical capacity, cognitive decline, symptoms of

90 depression, urine and bowel incontinence, and quality of life have a relationship among

91 these three levels of dependency.

92

93 Material and Method

94

Design and study population

96

97 A cross-sectional, observational, and descriptive study was conducted. The population that

98 participated in this study met the following inclusion criteria: i) people 60 years of age or

\footnotetext{
${ }^{1}$ The Barthel Index was designed to assess the level of dependency according to 10 activities of daily living (ADL) in institutionalized patients (10). Given its easy application and its good psychometric capabilities, this index has expanded its application to other contexts such as ambulatory rehabilitation units or for older adults living in the community (11). Within this framework, 5 cut-off points were proposed by Shah to differentiate selfreliant people from dependents: total dependency: 0-20; severe dependency: 21-60; moderate dependency: 6190; slight dependency: 91-99; Independence: 100, considering that people with values over 60 points are practically independent regarding their basic skills (12).
} 
99 older, ii) socially vulnerable (older adults who belong to $60 \%$ of the Chilean population with

100 less income or greater vulnerability, according to the registry social of homes) iii) residents

101 of the district of Puente Alto in Santiago, Chile, who were attending community elderly day

102 centers during August of 2018 (program that integrates older adults during the day, holding

103 a series of workshops that affect the personal, social and community sphere), iv) those who

104 have accepted and signed the informed consent according to current regulations and v)

105 those with a slight dependency or independent, whose Barthel Index was 60 to 100 points.

106 Older adults that according to the primary care center that either had functional or health

107 difficulties that would not allow them to participate in the intervention (e.g. Alzheimer or other

108 dementias), or that had evident cognitive deterioration that would not allow them to

109 understand the consent form, were excluded. Of the total of 528 people attending all the day

110 centers studied, $61 \%$ met the inclusion criteria ( $n=322$ older adults). All participants were

111 completed on their dependency and functionality levels.

113 Level of dependency:

115 To measure older adults independence and their ability to carry out activities of daily life

116 (ADL) considered as basic (10), the Barthel Index was used. This instrument generates a

117 score between 0 to 100 points that estimates the degree of independence of the person. A

118 score of 100 corresponds to a totally independent person, while a score of 0 is a person with

119 absolute dependence.

120

121 Functionality tests:

122 
123 The EQ-5D Index is based on five dimensions: mobility, personal care, habitual activity, 124 pain/discomfort and anxiety/depression ${ }^{2}$. The instrument generates combinations of 125 responses that form 243 possible profiles of health states, assigning to each profile a score 126 that ranges from -0.494 to 1 , where 0 is a state of dead health, 1 is a state of perfect health 127 and values less than 0 indicate worse states than being dead (14). A score of 0.457 or above 128 indicates a positive quality of life perception (14). To measure the fear of falling in older 129 adults, the Short FES I (Falls Efficacy Scale) questionnaire was used. This instrument 130 consists of 7 questions, each of them has four response categories, totaling 28 points ${ }^{3}$.

132 To measure physical condition, 3 instruments were used. Time Up-And-Go test (TUG), Five 133 times Sit to Stand test (TSS), and Self-selected walking speed (WST). TUG measures the 134 balance and mobility as the time between standing up, walk 3 meters, and sit down again of 135 older adults. It consists of getting up, walking 3 meters and sitting down again. A person 136 who takes more than 10 seconds to develop this test is considered to have impaired mobility 137 (17). Five times Sit to Stand test asks older adults to stand and sit in a chair 5 times, 138 recording the time it takes to develop the test. It evaluates the muscular strength of the lower 139 limbs and it is considered that if the person takes 12 seconds or more to finish the test, then 140 they have strength problems in their legs (18). The self-selected walking speed test asks 141 older adults to walk at a normal pace 6 meters, allowing the speed of walking to be 142 evaluated. If it travels less than 0.8 meters / second it means that it has some disorder in its 143 walking capacity (19).

\footnotetext{
${ }^{2}$ Each question is evaluated according to three possible answers; 1 = without problems, 2 $=$ with moderate problems and $3=$ with severe problems (13).

${ }^{3}$ Delbaere and collaborators established cut-off points to classify the risk of falls into: low, moderate and high risk, with scores of $7-8,9-13$ and $14-28$ respectively $(15,16)$.
} 
145 To detect cognitive impairment, the Memory Impairment Screen (MIS) instrument was used

146 (20). This instrument asks older adults to memorize 4 words from different semantic

147 categories. After 2-3 minutes they are asked to repeat them; 2 points are awarded for each

148 word remembered spontaneously and 1 point is awarded for each word remembered with

149 help. The score ranges from 0 to 8 . A score of 5 points and less suggests cognitive decline

150 (21), and to detect symptoms of depression, the abbreviated Yesavage Index was used ${ }^{4}$. A

151 score of 2 or more positive responses suggests depression (23).

153 Finally, to determine their sociodemographic level, we observed and measured for each

154 older adult, their gender, age, marital status, schooling, literacy, and whether they lived

155 alone or accompanied. And to determine their health status, we measured through a self-

156 answered questionnaire, their history of smoking, medication consumption, calf

157 circumference as an indicator of risk of malnutrition $(24,25)$, number of diseases at the

158 moment as a measure of comorbidity, and body mass index (BMI kg / mts2) as an indicator

159 of nutritional status (26).

160

161

Data registration procedure

162

163 The data capture was done in REDCap (27), a software that operates in web browsers and

164 that allows the online construction and management of the database. The data was collected

165 through different surveys that consolidated all the variables and instruments described

166 above.

167

${ }^{4}$ The 5 -item version was found to be as effective as the 15-question version and even more so when applied on a population scale, with a sensitivity of $97 \%$ and a specificity of $85 \%$ for the diagnosis of depression (22). In Chile it proved to be effective as a screening instrument, with good sensitivity, specificity, and positive and negative predictive values. 
168 The surveys were applied by trained personnel through workshops that included the

169 explanation of the content of the instruments, their measurement and a demonstration of the

170 operation of the data capture software. Subsequently, a role play was carried out where the

171 interviewers exercised the application of the instrument among themselves, thus being able

172 to practice and solve their questions.

173

174 Analysis of Data

175

176 Older adults were classified into 3 groups according to the Barthel Index as proposed by

177 Shah: independent (score 100 points), moderate dependency (91 to 99 points), and slight

178 dependency (60 to 90 points) (12). These 3 groups were then classified by age, gender,

179 education level, literacy, whether living alone or accompanied, marital status, number of

180 comorbidities, and BMI. Table 1 presents the frequencies, percentages per group and test

181 of proportions ${ }^{5}$. All the analysis was done at $95 \%$ statistical confidence.

182

183 Each older adult was classified with either independent Barthel Index (100 score) or slight

184 to moderate dependency Barthel Index (60 to 99 score) to establish which of the 10 Barthel

185 activities were the most important ones which determine the final Barthel Index.

186 To examine the impact of dependency on quality of life, a multivariate linear regression was

187 conducted to predict quality of life (EQ5D score) from changes between moderate 188 dependency, slight dependency, and independence controlling for all the socio189 demographic and health variable we were able to observe (age, gender, education, civil 190 status, live alone, number of comorbidities, and BMI):

191

\footnotetext{
${ }^{5}$ All the analyses were performed in the R software, version 4.0.3 (28).
} 


$$
\ln \left(E Q 5 D_{i}\right)=\alpha_{i}+\beta_{1 i} \text { Barthel }_{i}+\beta_{c i} \text { Controls }_{i}+\varepsilon_{i}
$$

194 Where, Barthel $l_{i}$ represents 3 dummy variables. One where the observation is equal to 1 if 195 subject $i$ had a score between 91 and 99 , and zero otherwise; the second equal to 1 if subject $196 i$ had a score equal to 100, and zero otherwise; Controls represents each of the

197 demographic and health variables observed for subject $i$, and $\varepsilon_{i}$ is the error term.

199 Finally, Barthel activities were cross tabulated above or below the cutoff level of normality 200 for EQ-5D, TUG, and Yesavage scores. They were analyzed according to how many 201 participants were above each cutoff level for the Barthel Index groups. 202

\section{Ethical Considerations}

205 The project and the informed consent were reviewed and approved by the Scientific Ethics

206 Committee of the Universidad de los Andes, Santiago - Chile, Code CEC201866, from

207 October-2018, according to current Chilean regulations (Law 20 120) (29).

209 Before starting the measurements and carrying out the surveys, a general meeting was held

210 to explain the objectives of the study and later the senior citizens were informed about these

211 objectives, the measurements, the benefits, the possible risks, and above all the willingness

212 to participate. After that, each person signed the informed consent. The identity of the 213 participants was protected by encrypting sensitive data and and limiting access to Protected 214 Health Information.

215

\section{Results}


218 Participants were evaluated using all the tests and indicators. Out of the total older adults,

219322 participants fulfilled all the requisites of eligibility. 73 or $23 \%$ of all older adults were 220 classified as moderate dependent, 76 or $24 \%$ of all older adults as slight dependent, and 221173 (53\% of all older adults) as independent. $60 \%$ of the participants were between 60 and 22274 years old, most of them were female (75\%) and lived with someone else (68\%). Also, 223 most the participants had at least 3 diseases (59\%).

225 Through tests of equality of proportions (test whether the three groups of older adults 226 classified by Barthel Index have the same proportions or not), it was determined that among 227 all sociodemographic and health measures, there were statistical differences in dependency 228 classification for older adults living alone.

230 A high proportion of independent older adults have also high levels of quality of life (EQ5D),

231 better performance in mobility tests, lower levels of fear of falling, and lower levels of 232 symptoms of depression. The biggest differences between no dependence and moderate 233 dependence were for quality of life and mobility. From all older adults classified as moderate 234 dependency (73 older adults), 44 of them or $60 \%$ were classified with low quality of life with 235 EQ-5D score of less than 0.457. In contrast, from all older adults classified as independent 236 (173 older adults), only 24 or $14 \%$ were found to have low quality of life. For TUG score, 237 there were also a difference of $46 \%$ between independence and moderate dependence 238 groups: $69 \%$ of all dependent older adults were found to take more than 10 seconds to get 239 up and go, but only $23 \%$ of independent older adults were found to take more than 10 240 second. From all the scores estimated, the MIS score and Five Sit to Stand test score were 241 the only ones that were not significantly different between dependency groups. See Table 1 242 and Figure 1 below for these differences. 
Table 1. Physical and cognitive evaluations of older adults according to Barthel Index groups

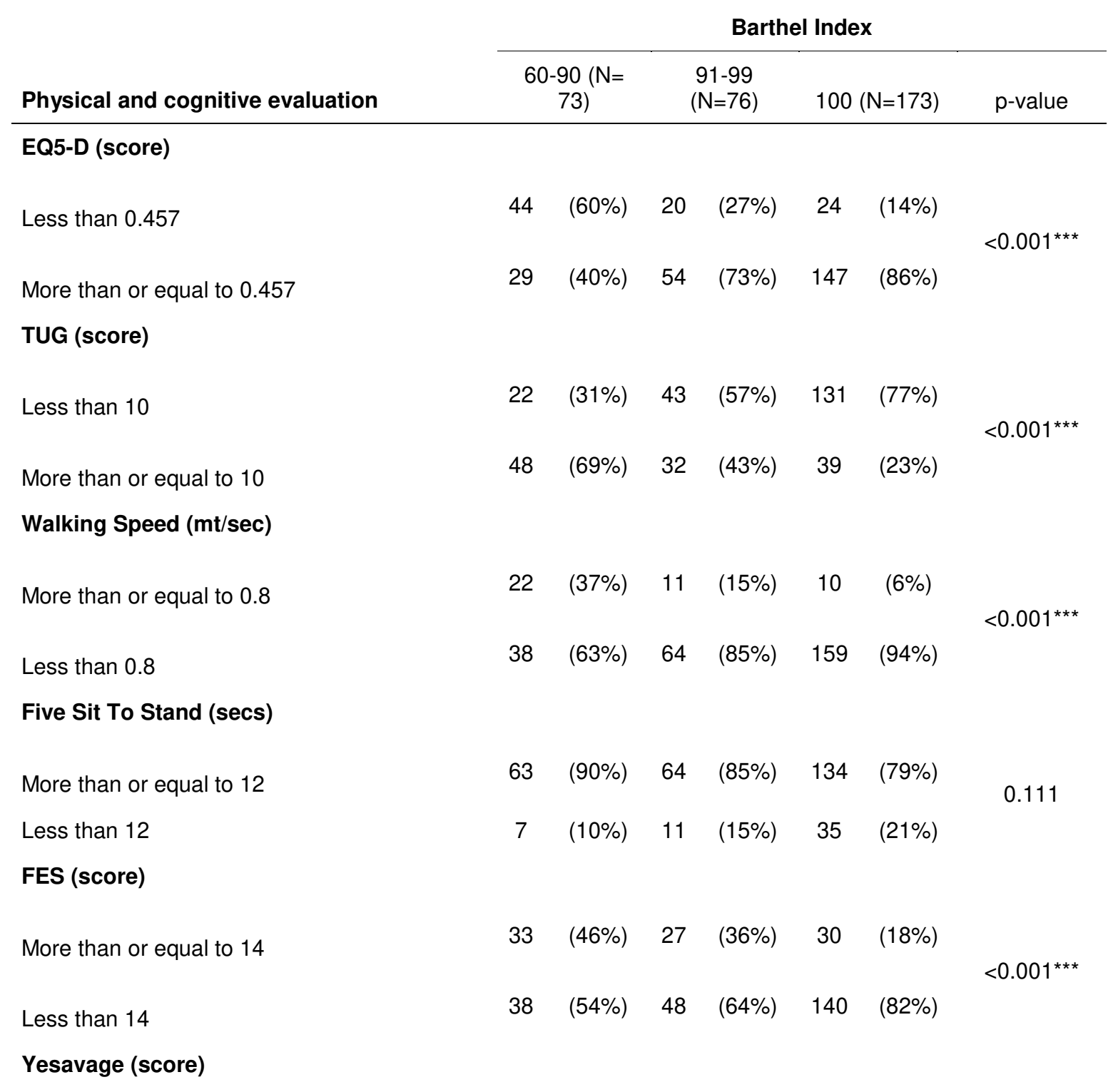




\begin{tabular}{lcccccccc} 
Less than 2 & 44 & $(62 \%)$ & 56 & $(75 \%)$ & 149 & $(88 \%)$ & $<0.001^{* \star *}$ \\
More than or equal to 2 & 27 & $(38 \%)$ & 19 & $(25 \%)$ & 21 & $(12 \%)$ & \\
MIS (score) & & & & & & & \\
More than 5 & 63 & $(86 \%)$ & 70 & $(92 \%)$ & 159 & $(92 \%)$ & 0.342 \\
Less than or equal to 5 & 10 & $(14 \%)$ & 6 & $(8 \%)$ & 14 & $(8 \%)$ & \\
\hline
\end{tabular}

$252{ }^{*}$ According to the categorization of the Barthel Index. Not necessarily each characteristic adds up to the total 253 Older adults since some of these were not evaluated in their entirety.

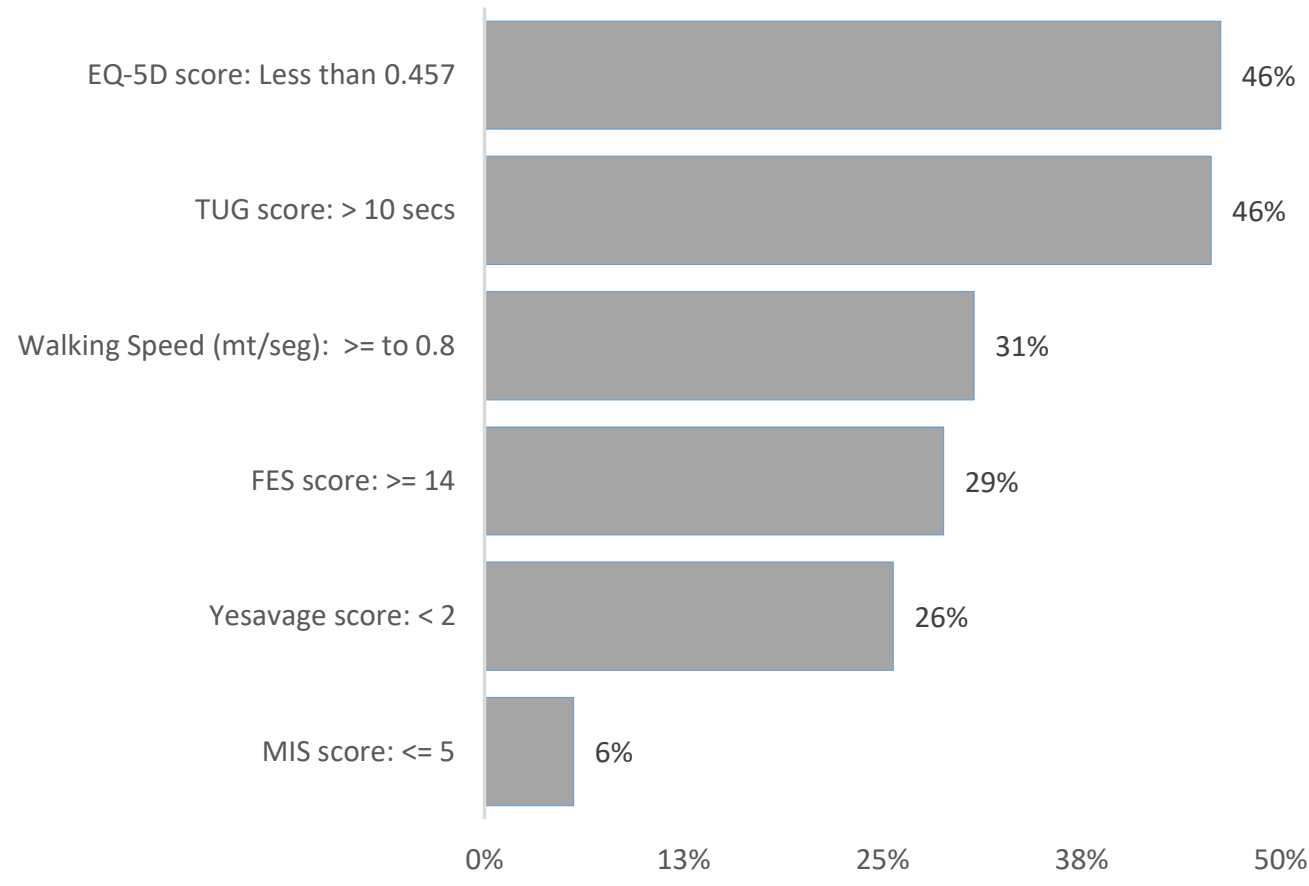

Figure 1. Difference between percentages of Barthel moderate dependence (60-90) and independence (100) for each score.

257 Note: The percentage for each score is calculated taking the difference between the percentage of older adults 258 classified as independent and moderate dependency. For example, for EQ-5D score, $60 \%$ of all older adults 259 were either slight or moderate dependent (less than 0.457 points in the EQ-5D test) and $14 \%$ of all older adults 260 were independence (higher than 0.457 points in the EQ-5D test). The difference of $46 \%$ is reflected in this Figure. 
262 Even a small reduction in dependency had a significant increase in health-related quality of

263 life. An increase from a 60-90 score (referential group) to a 91-99 score in the Barthel Index

264 rises 42\% [CI95\% 18-66] the EQ-5D score and 49\% [CI95\% 29-70] for full independence.

265 Table 2 shows the coefficients from the multivariate linear regression and Figure 2 presents

266 a graphical representation of the difference in distribution between the three Barthel groups

267 for EQ-5D score. The regression coefficients for the Barthel Index are interpreted as the

268 difference in percentages between a Barthel Index lower or equal than 90 (moderate

269 dependency) and either Barthel Index of 91 to 99 (slight dependency) or Barthel Index equal

270 to 100 (independence).

Table 2. Multivariate Linear Regression between quality of life (EQ-5D) and dependency groups (Barthel Index)

Independent variable:

$\operatorname{Ln}(E Q 5 D)$

\begin{tabular}{lccccc}
\hline & \multicolumn{7}{c}{ Std. } & & \\
& Coefficient & Error & t value & $\operatorname{Pr}(>|\mathrm{t}|)$ & $\mathrm{Cl}(95 \%)$ \\
\hline Constant & -0.99 & 0.7 & -1.399 & 0.16 & {$[-2.37,040]$} \\
Barthel Index score $=91$ to 99 & 0.42 & 0.12 & 3.508 & $0.00^{\text {*** }}$ & {$[0.18,0.66]$} \\
Barthel Index score $=100$ & 0.49 & 0.1 & 4.713 & $0.00^{\text {*** }}$ & {$[0.29,0.70]$} \\
\hline
\end{tabular}

Controls: Age, gender, educational level, civil status, live alone, comorbidity, and BMI

R-square 0.12

Observations 292

Note: $p$-value $<0.01^{* * *} ; p$-value $<0.05^{* *} ; p$-value $<0.1^{*}$

Referential group: Barthel Index score $=60-90$ (moderate dependency)

271 


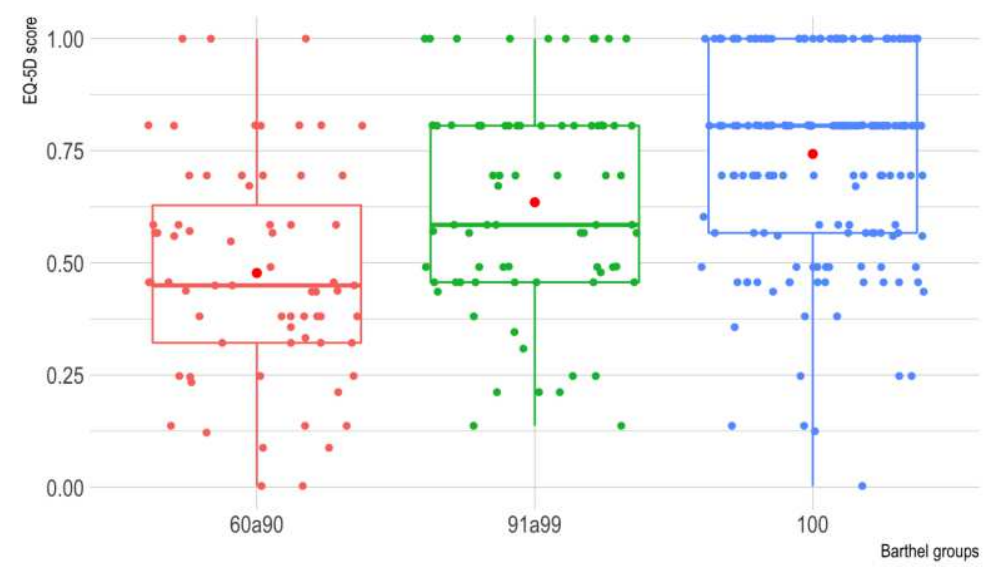

275 Figure 2. Boxplot of EQ-5D score for the $\mathbf{3 2 2}$ older adults clustered by group of

276 dependency.

277 Note: The red dot in each box represents the mean value for that group.

279 Climbing stairs and incontinence in urination are the two main activities related to having 280 some dependence (slight to moderate dependence with Barthel Index lower than 100 281 points). Figure 3 presents the percentage differences per Barthel activity. We estimated the 282 percentage of older adults who had a lower than the maximum score for each of the Barthel 283 activities and we observe that $22.4 \%$ of all older adults have lower score than the maximum 284 due to a deficit in climbing stairs and $21.7 \%$ of all older adults have lower score than the 285 maximum for incontinence. The other activities show not significantly difference between the 286 proportions. 


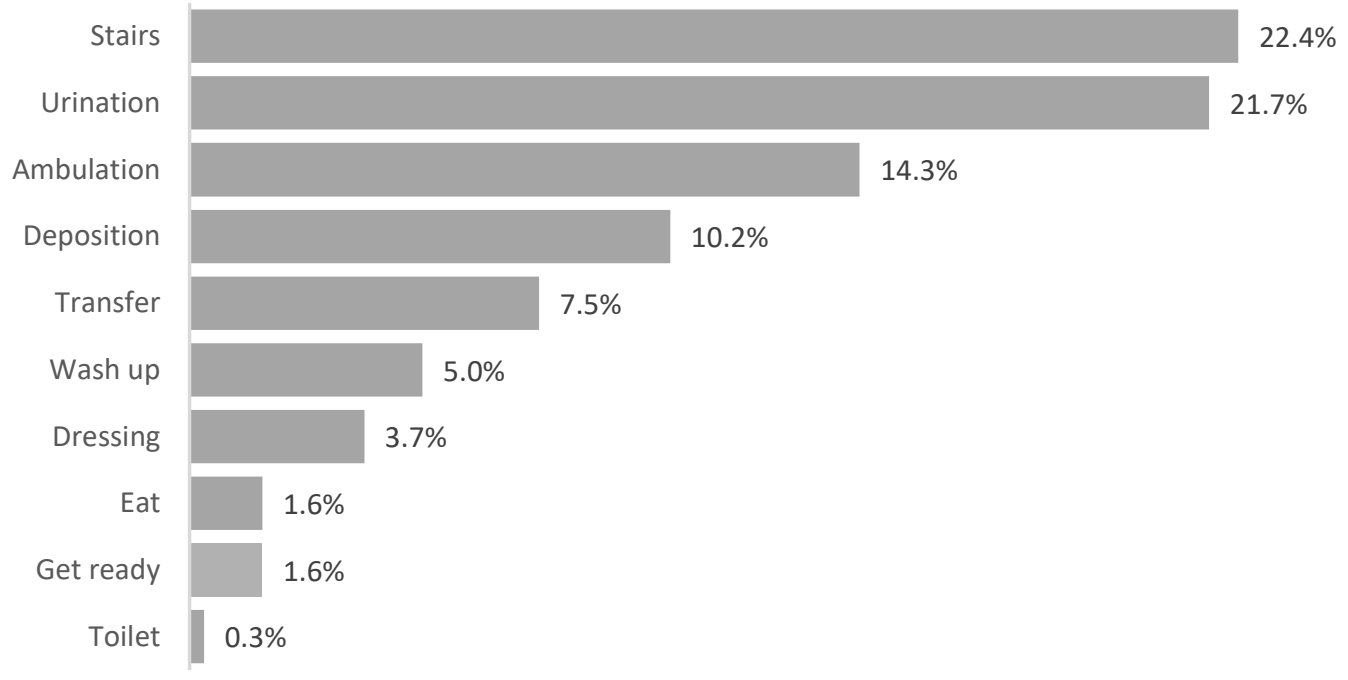

289 Figure 3: Percentage of older adults with Barthel Index less than maximum score 290 per activity.

291 Note: (a) Each percentage per activity was calculated by as the number of older adults with a score lower than 292 the maximum score for that activity divided by the 322 older adults. For example, for climbing stairs, 72 out of 293 the 322 older adults scored less than 10 points (max score). (b) ${ }^{* * \star}$ test of proportions $p$-value $<0.05$.

295 Ambulation and climbing stairs are the two main activities related with lower than the cutoff 296 levels for quality of life (EQ-5D) and physical condition (TUG). Figure 4 presents the 297 percentage differences for EQ-5D and Barthel index. When Barthel activities were analyze 298 one by one, it was observed that activities related with movement like ambulation, climbing 299 stairs, transfer from one place to another have a higher difference on how older adults 300 scored in terms of quality of life or physical condition. 


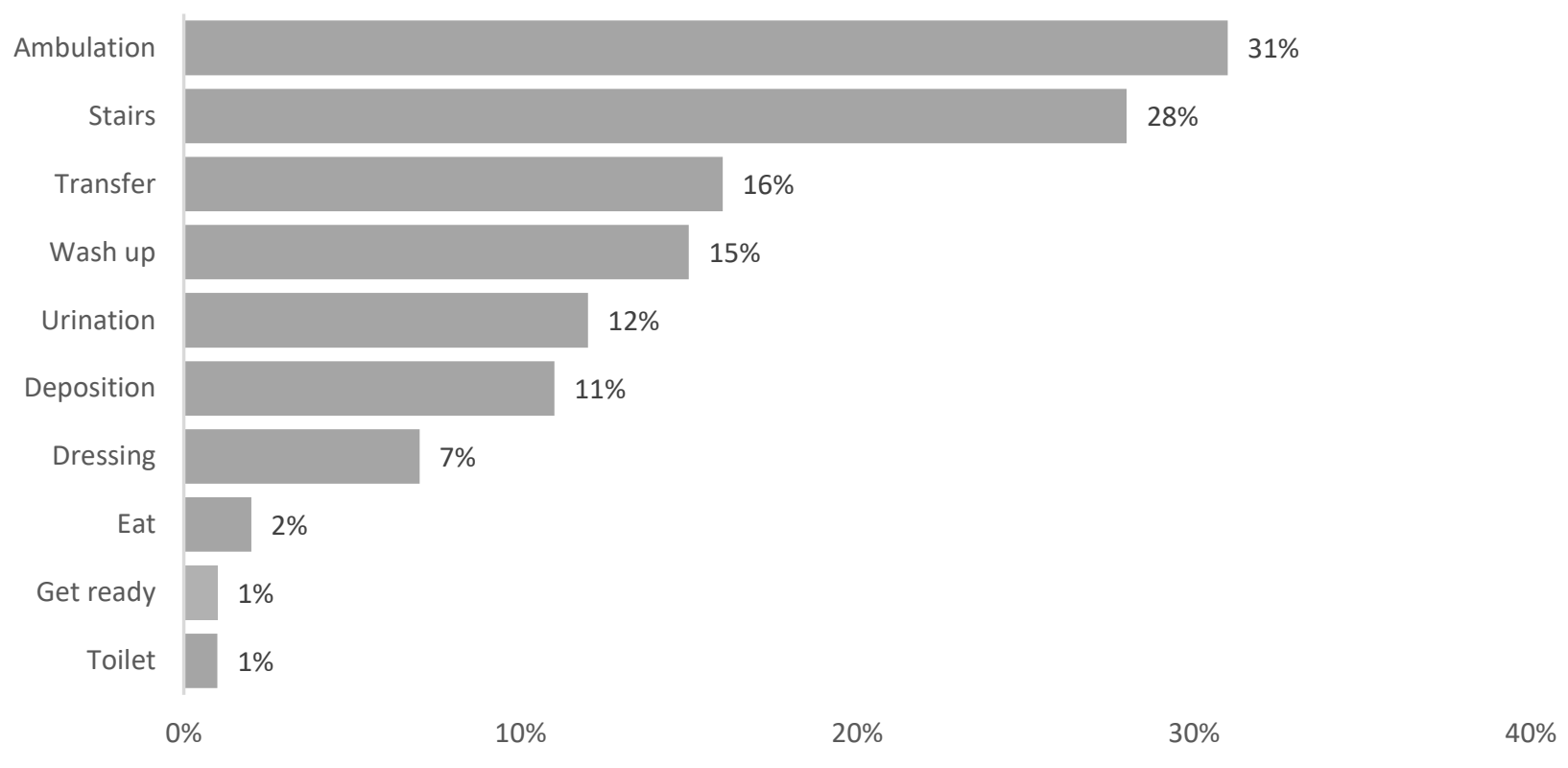

Figure 4. Difference between percentage of older adults over and under 0.457 EQ-5D

304 scores by Barthel activity.

305 Notes: (a) The percentage for each activity is calculated taking the difference between the percentage of older

306 adults classified above or below the EQ-5D cutoff score of 0.457 for all older adults classified with maximum

307 score for that activity. For example, for ambulation, $93 \%$ of all older adults with a higher score than 0.457

308 points in the EQ-5D test scored also the maximum score for ambulation in the Barthel Index, but only $63 \%$ of

309 all older adults with a lower score than 0.457 points in the EQ-5D test scored also the maximum for ambulation

310 in the Barthel Index. The difference of $31 \%$ is reflected in this Figure. (b) ${ }^{* \star *}$ test of proportions $p$-value $<0.05$.

312 Urine and bowel incontinence, and ambulation are the three main activities related with

313 levels of depression symptoms (Yesavage score). These activities had the most significant

314 difference between moderate dependence and independence in how older adults scored in

315 the Yesavage test. Compared with quality of life and physical condition, the differences in

316 activities with respect to Yesavage were smaller. Figure 5 presents the percentages

317 differences for Yesavage and Barthel index. 


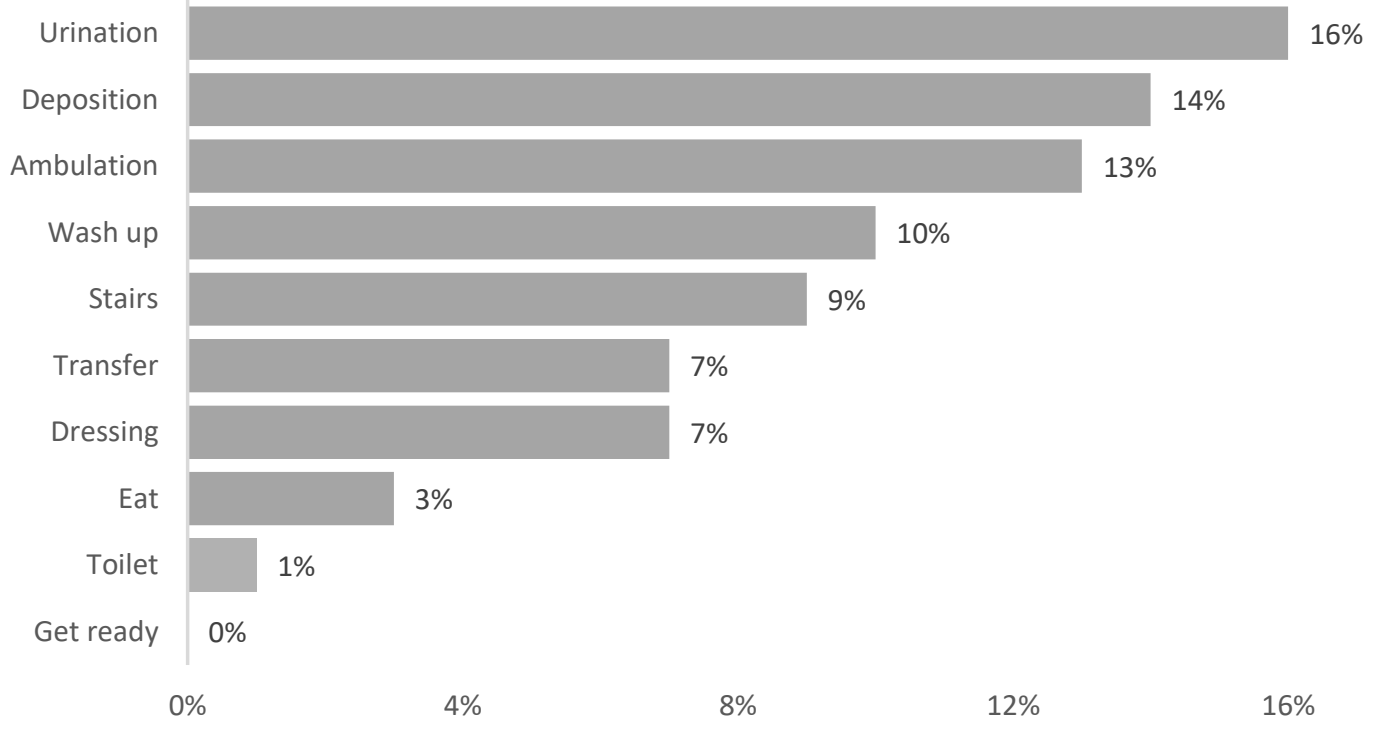

\section{Figure 5. Difference between percentage of older adults over and under 2 points for}

\section{3 the Yesavage score by Barthel activity.}

324 Note: (a) The percentage for each activity is calculated taking the difference between the percentage of older

325 adults classified above or below the Yesavage cutoff score of normality (score of 2) for all older adults

326 classified with maximum score for that activity. For example, for incontinence of urination $82 \%$ of all older

327 adults with a lower than 2 points in the Yesavage test scored the maximum for incontinence of urination in the

328 Barthel Index, but only $66 \%$ of all older adults with a higher score than 2 points in the Yesavage test scored

329 also the maximum for incontinence of urination in the Barthel Index. The difference of $16 \%$ between these two

330 percentages is reflected in this Figure. (b) ${ }^{* \star *}$ test of proportions $p$-value $<0.05$.

332 Finally, gender, education level, literacy, number of comorbidities, memory score (MIS), and

333 civil status do not show a significant relationship with proportion of older adults in either

334 independence (100 score in Barthel) or moderate/slight dependence (less than 100 score in

335 Barthel). For older adults living alone, there is a significant difference in proportions between

336 dependencies where older adults with no dependency tend to live alone more frequently.

337 For example, only $19 \%$ of older adults with moderate dependence were living alone

338 compared with $33 \%$ of all older adults with no dependence. Table 3 presents the 
339 classification of all older adults by socio-demographic and health variables observed by 340 Barthel group.

Table 3. Socio-demographic and anthropometric characteristics of the older adults by Barthel group

Barthel Index

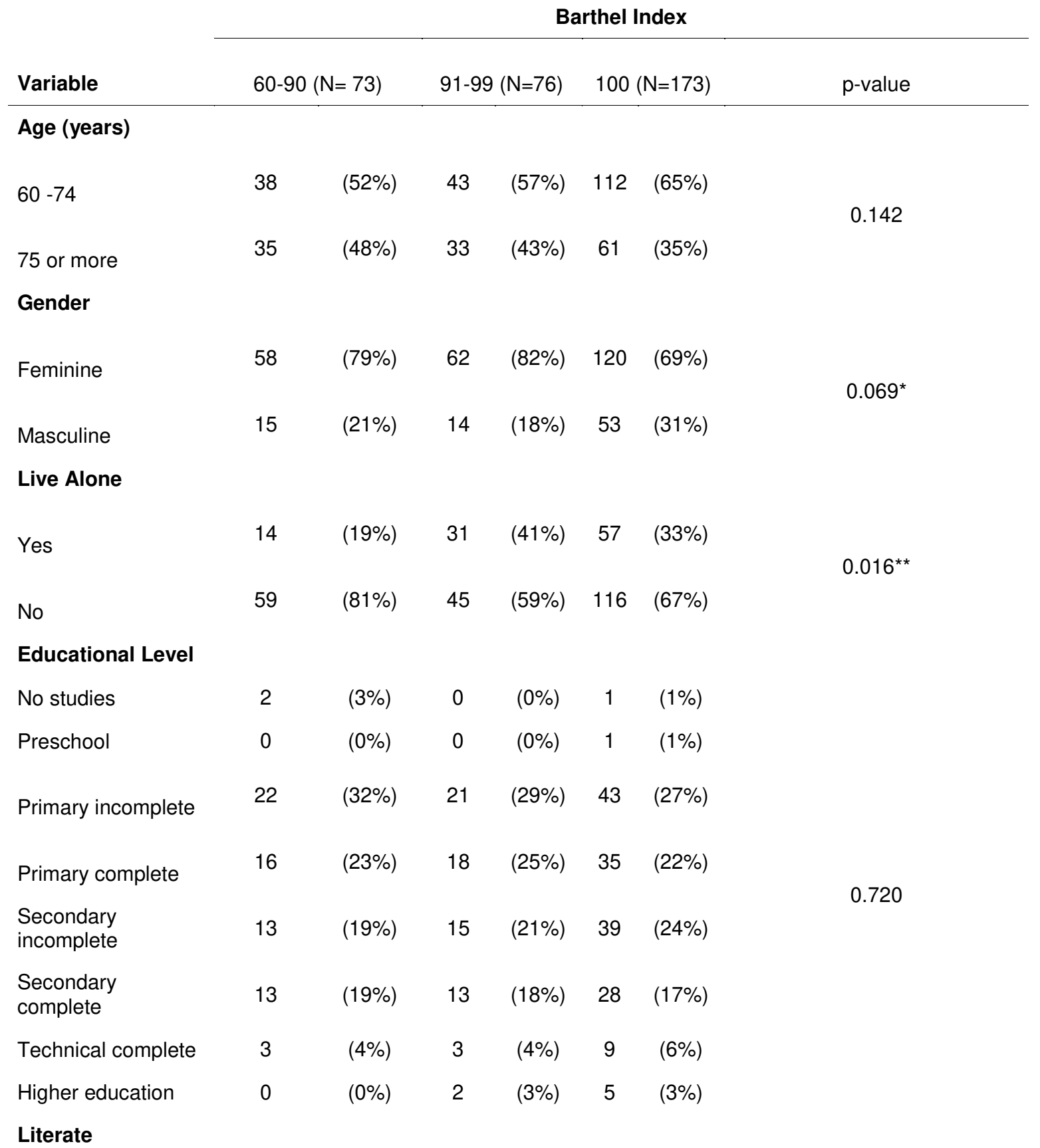




\begin{tabular}{|c|c|c|c|c|c|c|c|}
\hline Yes & 69 & (95\%) & 72 & $(95 \%)$ & 161 & $(93 \%)$ & 0.843 \\
\hline No & 4 & $(5 \%)$ & 4 & $(5 \%)$ & 12 & $(7 \%)$ & \\
\hline \multicolumn{8}{|l|}{ Marital Status } \\
\hline Married & 34 & $(47 \%)$ & 35 & $(46 \%)$ & 81 & $(47 \%)$ & \\
\hline Widowed & 24 & $(33 \%)$ & 21 & $(28 \%)$ & 33 & $(19 \%)$ & \\
\hline Single & 10 & $(14 \%)$ & 10 & $(13 \%)$ & 35 & $(20 \%)$ & 0.994 \\
\hline Separated & 3 & $(4 \%)$ & 8 & $(11 \%)$ & 13 & $(8 \%)$ & \\
\hline Divorced & 1 & $(1 \%)$ & 1 & $(1 \%)$ & 9 & $(5 \%)$ & \\
\hline Cohabit & 1 & $(1 \%)$ & 1 & $(1 \%)$ & 2 & $(1 \%)$ & \\
\hline \multicolumn{8}{|l|}{ BMI } \\
\hline Emaciated & 7 & $(10 \%)$ & 7 & $(9 \%)$ & 11 & $(6 \%)$ & \\
\hline Normal & 15 & $(21 \%)$ & 23 & $(31 \%)$ & 71 & $(42 \%)$ & \\
\hline Overweight & 26 & $(36 \%)$ & 21 & $(28 \%)$ & 47 & $(27 \%)$ & 0.430 \\
\hline Obese & 25 & $(34 \%)$ & 23 & $(31 \%)$ & 42 & $(25 \%)$ & \\
\hline \multicolumn{8}{|l|}{ Comorbidities } \\
\hline $\begin{array}{l}\text { More than or equal } \\
\text { to } 3\end{array}$ & 48 & $(66 \%)$ & 49 & $(64 \%)$ & 94 & $(54 \%)$ & \multirow{2}{*}{0.144} \\
\hline Less than 3 & 25 & $(34 \%)$ & 27 & $(36 \%)$ & 79 & $(46 \%)$ & \\
\hline
\end{tabular}

345 Discussion

347 One of the most important concerns for older adults is losing their independence; $67 \%$ of all 348 older adults surveyed in Chile expressed this opinion in the V Encuesta Nacional de Calidad 349 de Vida en la Vejez in 2019 (6). Activities of daily living (ADL) allow older adults more or less 350 independence which is closely related to functionality, that is, having the physical and / or 
351 mental capacity to perform ADLs. Barthel is currently considered a relevant instrument to

352 identify the deterioration of the first ADLs in older adults during the natural aging process. It

353 is a long-standing instrument, recognized in its application in dependent and institutionalized

354 people, which allows determining the state of dependency.

356 Through this study, carried out on 322 older adults aged 60 and over who attend day centers

357 in Santiago, Chile, we have been able to associate the categories of the Barthel Index with

358 quality of life, cognitive capacity and functional activities of the participants. Using cut-off

359 points from the literature to distinguish normality in the measurements, we observe the

360 usefulness of the Barthel Index in an independent population.

362 The categorization provided by Barthel allows to identify some of the activities that are 363 associated with slight levels of dependency, and these may be predictors of functional 364 deterioration. Although, people with a slight loss of functionality are still considered highly 365 independent according to the Barthel Index, this study provides evidence such as how 366 independence is related with high levels of quality of life (EQ-5D) and mobility (especially 367 inside the house), and how quality of life raises significantly among independent older adults 368 compared with older adults who are slight or moderate dependent. It also provides evidence

369 on how climbing stairs and urine incontinence are some of functions of daily life that 370 deteriorate even when older adults are considered independent, and how the deterioration 371 of these functions together with incontinence of depositions are related with symptoms of 372 depression.

374 These differences in activities and how they associate with dependency are very important 375 if one's goal is to increase older adults' quality of life and reduce symptoms of depression. 376 For example, urine incontinence has a negative impact in quality of life, self-esteem, and 
377 social interaction of older adults which it is turned into incapacity to work and depression 378 (30).

380 Multidimensional programs that target older adults that could detect and target earlier loss 381 of functionality and help them increase mobility and reduce incontinence in urination might 382 help raise quality of life in their current stage and reduce symptoms of depression, might 383 help to prolong their state of independence. Research suggests that the multidimensional 384 programs that include cardiovascular, resistance, balance, including cardiovascular and 385 motor fitness training might achieve good results not only in improving quality of life but also 386 cognitive improvements (31).

388 One of the limitations of this study is that it was carried out in community elderly day centers 389 in a single district of Santiago, where $80 \%$ of the attendees were women and heterogeneity 390 might have been sub-optimal. However, one of its strengths is that the measurements were 391 performed in a standardized way. High standards in procedures provide confidence in the 392 measurements. Measurements were carried out by students from health science programs 393 and professionals, who were previously trained, and the instruments used for the 394 measurements are validated in Chile. Also, data capture was done in a standardized way 395 using REDCap platform.

397 Understanding the potential causes of significant differences in older adults' dependency 398 could help prioritize the focus of multidimensional programs on health and prevention with 399 the aim of prolonging older adults state of independence and improving quality of life for 400 older adults with slight levels of dependency. In this study, $53 \%$ of older adults enjoy of total 401 independence, a fact that is in line with the integral geriatric evaluation done in 60 older 402 adults in Colombia, in which $47 \%$ of them were independents (32). Future research should 
try to answer whether multidimensional programs are effective in reducing dependency and

404 increasing quality of life.

405

406

407

408

409

410

411

412

413

414

415

416

417

418

419

420

421

422

423

424

425

426

427

428

429

430

431

432

433

434

435

436

437

438

439

440

441

442

443

444

445

446

447

448

449

450

451

\section{Declarations:}

\section{Ethics approval and consent to participate}

\section{Ethics Approval}

All procedures performed in studies involving human participants were in accordance with the ethical standards of the institutional and/or national research committee and with the 1964 Helsinki Declaration and its later amendments or comparable ethical standards and approved by the relevant institutional review boards.

Patient sera were collected in accordance with the code of conduct of research with human material in Chile. This study was approved by the ethical committee of Universidad de los Andes, also called 'Comité de Etica de Universidad de Los Andes'. The ethics committee, reviewed and approved this project and the informed consent to participate form with the code CEC201866, from October-2018, according to current Chilean regulations.

\section{Consent to participate}

Informed consent was obtained from each study participant after they were told of the potential risks and benefits as well as the investigational nature of the study.

\section{Conflict of Interest}

The authors declare that they have no conflicts of interest.

\section{Consent for publication}

Not applicable

\section{Availability of data and materials}

The data that support the findings of this study are available on request from the corresponding author, MTV. The data are not publicly available due to their containing information that could compromise the privacy of research participants.

\section{Competing interests}

None

\section{Funding}

Universidad de los Andes (Chile)

Authors' contributions 
452 YF, MTV, and PSM wrote the main manuscript with all its figures and tables.

453

454

MTV, CR, DG, AG, RGV, IP, MPU, and PSM conducted the intervention and collected the

455 data.

456

457

458

459

460

461

462

463

464

465

466

467

468

Acknowledgements

We are thankful to all the students in the Medicine Faculty at the University of los Andes and Puente Alto CEDIAM staff that helped us with the measurements and survey application during the study. We are also thankful for the invaluable advice that Dr. David Torres provided us with his comments.

\section{Authors' information}

Author for Mailings:

María Teresa Valenzuela

469 Av. Mons. Álvaro del Portillo 12.455

470 Las Condes, Santiago - Chile

$471 \quad$ mtvalenzuela@uandes.cl 
474 1. Thomas BThomas B. L. Kirkwood. Why and how are we living longer? Exp Physiol. $475 \quad 2017 ; 102.9: 1067-74$.

476 2. Edjolo A, Proust-Lima C, Delva F, Dartigues J-F, Pérès K. Natural History of Dependency in 477 the Elderly: A 24-Year Population-Based Study Using a Longitudinal Item Response Theory 478 Model. Am J Epidemiol. 2016 Feb 15;183(4):277-85.

479 3. Molina H, Sarmiento L, Aranco N, Jara P. Envejecimiento y atención a la dependencia en 480 Chile [Internet]. Inter-American Development Bank; 2020 Sep [cited 2020 Dec 31]. Available 481 from: https://publications.iadb.org/es/node/28903

482 4. Organización panamericana de la salud. Oficina Regional de la, OMS. Evaluación funcional 483 del Adulto Mayor. Parte I: Módulos de valoración clínica [Internet]. [cited 2019 Apr 23]. 484 Available from: http://www.sld.cu/galerias/pdf/sitios/gericuba/modulo3.pdf

485 5. Instituto Nacional de Estadísticas (INE) Chile - Censo 2017. Adultos mayores presentan 486 mayor dependencia y participación en el mercado laboral informal [Internet]. [cited 2020 Dec 487 30]. Available from: https://www.ine.cl/prensa/2019/09/16/adultos-mayores-presentan-mayor488 dependencia-y-participaci\%C3\%B3n-en-el-mercado-laboral-informal

489 6. Pontificia Universidad Católica de Chile, Caja Los Andes. Chile y sus Mayores: Quinta 490 Encuesta Nacional de Calidad de Vida en la Vejez 2019. [Internet]. [cited 2020 Nov 1]. $491 \quad$ Available from:

492 http://www.senama.gob.cl/storage/docs/QUINTA_ENCUESTA_NACIONAL_DE_CALIDA

493 D_DE_VIDA_EN_LA_VEJEZ_2019._CHILE_Y_SUS_MAYORES_2019.pdf 
494 7. Dependencia funcional en las personas mayores [Internet]. [cited 2019 Apr 23]. Available 495 from:

496 http://observatorio.ministeriodesarrollosocial.gob.cl/documentos/Panorama_Casen_Dependen 497 cia_funcional_personas_mayores_corr.pdf

498 8. Ministerio de Desarrollo social. Adultos mayores: Sintesis de resultados [Internet]. [cited 4992019 Apr 23]. Available from: http://observatorio.ministeriodesarrollosocial.gob.cl/casen500 multidimensional/casen/docs/CASEN_2015_Resultados_adultos_mayores.pdf

501 9. Villalobos Dintrans P. Panorama de la dependencia en Chile: avances y desafíos. Rev Médica $502 \quad$ Chile. 2019;147(1):83-90.

503 10. Mahoney FI., Barthel DW. Functional evaluation: The Barthel index. Md State Med J.

$504 \quad 1965 ; 14: 61-5$.

505 11. Cid-Ruzafa J, Damián-Moreno J. Valoración de la discapacidad física: el indice de Barthel.

506 Rev Esp Salud Pública. 1997 Mar;71(2):127-37.

507 12. Shah S, Vanclay F, Cooper B. Improving the sensitivity of the Barthel Index for stroke 508 rehabilitation. J Clin Epidemiol. 1989 Jan;42(8):703-9.

509 13. Rabin R, Charro F de. EQ-SD: a measure of health status from the EuroQol Group. Ann Med. $510 \quad 2001$ Jan;33(5):337-43.

511 14. Shaw JW, Johnson JA, Coons SJ. US Valuation of the EQ-5D Health States: Development 512 and Testing of the D1 Valuation Model. Med Care. 2005 Mar;43(3):203-20.

513 15. Delbaere K, Close JCT, Mikolaizak AS, Sachdev PS, Brodaty H, Lord SR. The Falls Efficacy 514 Scale International (FES-I). A comprehensive longitudinal validation study. Age Ageing. $515 \quad 2010$ Mar 1;39(2):210-6. 
516 16. Yardley L, Beyer N, Hauer K, Kempen G, Piot-Ziegler C, Todd C. Development and initial

517 validation of the Falls Efficacy Scale-International (FES-I). Age Ageing. 2005 Nov

$518 \quad 1 ; 34(6): 614-9$.

519 17. Shumway-Cook A, Brauer S, Woollacott M. Predicting the Probability for Falls in

520 Community-Dwelling Older Adults Using the Timed Up \&amp; Go Test. Phys Ther. 2000

$521 \quad$ Sep 1;80(9):896-903.

522 18. Buatois S., Miljkovic D., Manckoundia P., Gueguen R., Miget P., Vancon G., et al. Five times

523 sit to stand test is a predictor of recurrent falls in healthy community-living subjects aged 65

$524 \quad$ and older. J Am Geriatr Soc. 2008;Aug;56(8):1575-7.

525 19. Bohannon RW. Comfortable and maximum walking speed of adults aged 20-79 years:

526 reference values and determinants. Age Ageing. 1997;26(1):15-9.

527 20. Buschke H, Kuslansky G, Katz M, Stewart WF, Sliwinski MJ, Eckholdt HM, et al. Screening

528 for dementia with the Memory Impairment Screen. Neurology. 1999 Jan 1;52(2):231-231.

529 21. Barrero-Hernández FJ, Vives-Montero F, Morales-Gordo B. Evaluation of the Spanish

530 version of the Memory Impairment Screen. Jul 1-15. 2006;43(1):15-19.

531 22. Hoyl MT, Alessi CA, Harker JO, Josephson KR, Pietruszka FM, Koelfgen M, et al.

532 Development and Testing of a Five-Item Version of the Geriatric Depression Scale. J Am

$533 \quad$ Geriatr Soc. 1999;47(7):873-8.

534 23. Hoyl M T, Valenzuela A E, Marín L PP. Depresión en el adulto mayor: evaluación preliminar

535 de la efectividad, como instrumento de tamizaje, de la versión de 5 ítems de la Escala de

536 Depresión Geriátrica. Rev Médica Chile. 2000 Nov;128(11):1199-204. 
537 24. López Lirola EM. La circunferencia de la pantorrilla como marcador rápido y fi able de 538 desnutrición en el anciano que ingresa en el hospital. Relación con la edad y sexo del paciente. 539 Nutr Hosp [Internet]. 2016 Jun 30 [cited 2019 Dec 18];33(3). Available from:

$540 \quad$ http://revista.nutricionhospitalaria.net/index.php/nh/article/view/262

541 25. M. Cuervo, D. Ansorena, A. García, M. A. González Martínez, I. Astiasarán, J. A. Martínez. 542 Valoración de la circunferencia de la pantorrilla como indicador de riesgo de desnutrición en 543 personas mayores. Nutr Hosp. 2009;24(1):63-7.

544 26. Ministerio de Salud. Gobierno de Chile. Orientación técnica para la atención de salud de las 545 personas adultas mayores en atención primaria [Internet]. [cited 2019 Apr 23]. Available 546 from: http://www.repositoriodigital.minsal.cl/handle/2015/440

547 27. Harris PA, Taylor R, Thielke R, Payne J, Gonzalez N, Conde JG. Research Electronic Data 548 Capture (REDCap) - A metadata-driven methodology and workflow process for providing 549 translational research informatics support. J Biomed Inform. 2009 Apr;42(2):377-81.

28. R: The R Project for Statistical Computing [Internet]. [cited 2019 Apr 23]. Available from: https://www.r-project.org/

29. LEY-20120 22-SEP-2006 MINISTERIO DE SALUD, SUBSECRETARÍA DE SALUD PÚBLICA - Ley Chile - Biblioteca del Congreso Nacional [Internet]. [cited 2019 Apr 23]. Available from: https://www.leychile.cl/Navegar?idNorma=253478

30. Robles JE. La Incontinencia Urinaria. An Sis San Navar. 2006;29(2):219-31. exercise on cognitive and physical functioning and brain-derived neurotrophic factor in older women: a randomised controlled trial. Age Ageing. 2014 Sep;43(5):623-9. 
32. Cortés N AR, Villarreal R E, Galicia R L, Martínez G L, Vargas D ER. Evaluación geriátrica integral del adulto mayor. Rev Médica Chile. 2011 Jun;139(6):725-31.

561 33. Tercera Encuesta Nacional de Salud refleja mejoras significativas en el desarrollo funcional 562 de niños y niñas - Ministerio de Salud - Gobierno de Chile [Internet]. [cited 2021 Jan 21]. 563 Available from: https://www.minsal.cl/tercera-encuesta-nacional-de-salud-refleja-mejoras564 significativas-en-el-desarrollo-funcional-de-ninos-y-ninas/

565 34. Hurvitz EA, Richardson JK, Werner RA, Ruhl AM, Dixon MR. Unipedal stance testing as an 566 indicator of fall risk among older outpatients. Arch Phys Med Rehabil. 2000 May;81(5):58756791.

568 35. Monsalves MJ, Mañalich J, Fuentes E. Validación del test Short Assessment of Health 569 Literacy for Spanish-speaking Adults en Chile, para medir alfabetización en salud. Rev $570 \quad$ Médica Chile. 2016 May;144(5):604-10.

571 36. Leyton Marta, Lobato Susana, Batista Marco, Aspano Mª Isabel, Jiménez Ruth. Validación 572 del cuestionario de estilo de vida saludable (EVS) en una población española. Rev Iberoam $573 \quad$ Psicol Ejerc El Deporte. 13(1):23-31.

574 37. Fernández-Rosati J, Lera L, Fuentes-López E, Albala C. Validez y confiabilidad del 575 cuestionario Eating Assessment Tool 10 (EAT-10) para detectar disfagia en adultos mayores 576 chilenos. Rev Médica Chile. 2018 Sep;146(9):1008-15.

577 38. Oral health surveys: basic methods [Internet]. [cited 2021 Jan 21]. Available from: 578 https://apps.who.int/iris/handle/10665/97035

579 39. Cirigliano G, Villaverde A. Dinámica de grupos y educación: fundamentos y técnicas. Buenos $580 \quad$ Aires: Humanitas; 1994. 
581 40. Sherbourne CD, Stewart AL. The MOS social support survey. Soc Sci Med. 1991

582 Jan;32(6):705-14.

583 


\section{Figures}

EQ-5D score: Less than 0.457

TUG score: $>10$ secs

Walking Speed (mt/seg): >= to 0.8

FES score: > $=14$

Yesavage score: $<2$

MIS score: $<=5$

$0 \%$

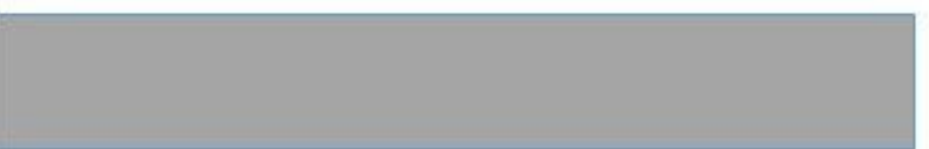

$46 \%$

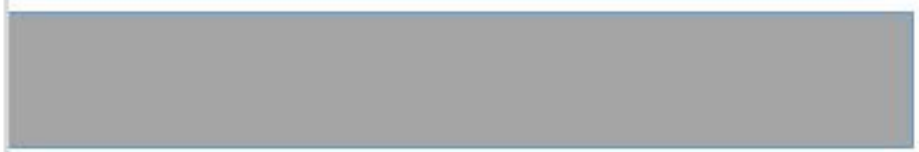

$46 \%$

\section{$31 \%$}

$29 \%$

$26 \%$

\section{Figure 1}

Difference between percentages of Barthel moderate dependence (60-90) and independence (100) for each score. Note: The percentage for each score is calculated taking the difference between the percentage of older adults classified as independent and moderate dependency. For example, for EQ-5D score, $60 \%$ of all older adults were either slight or moderate dependent (less than 0.457 points in the EQ$5 \mathrm{D}$ test) and $14 \%$ of all older adults were independence (higher than 0.457 points in the EQ-5D test). The difference of $46 \%$ is reflected in this Figure. 


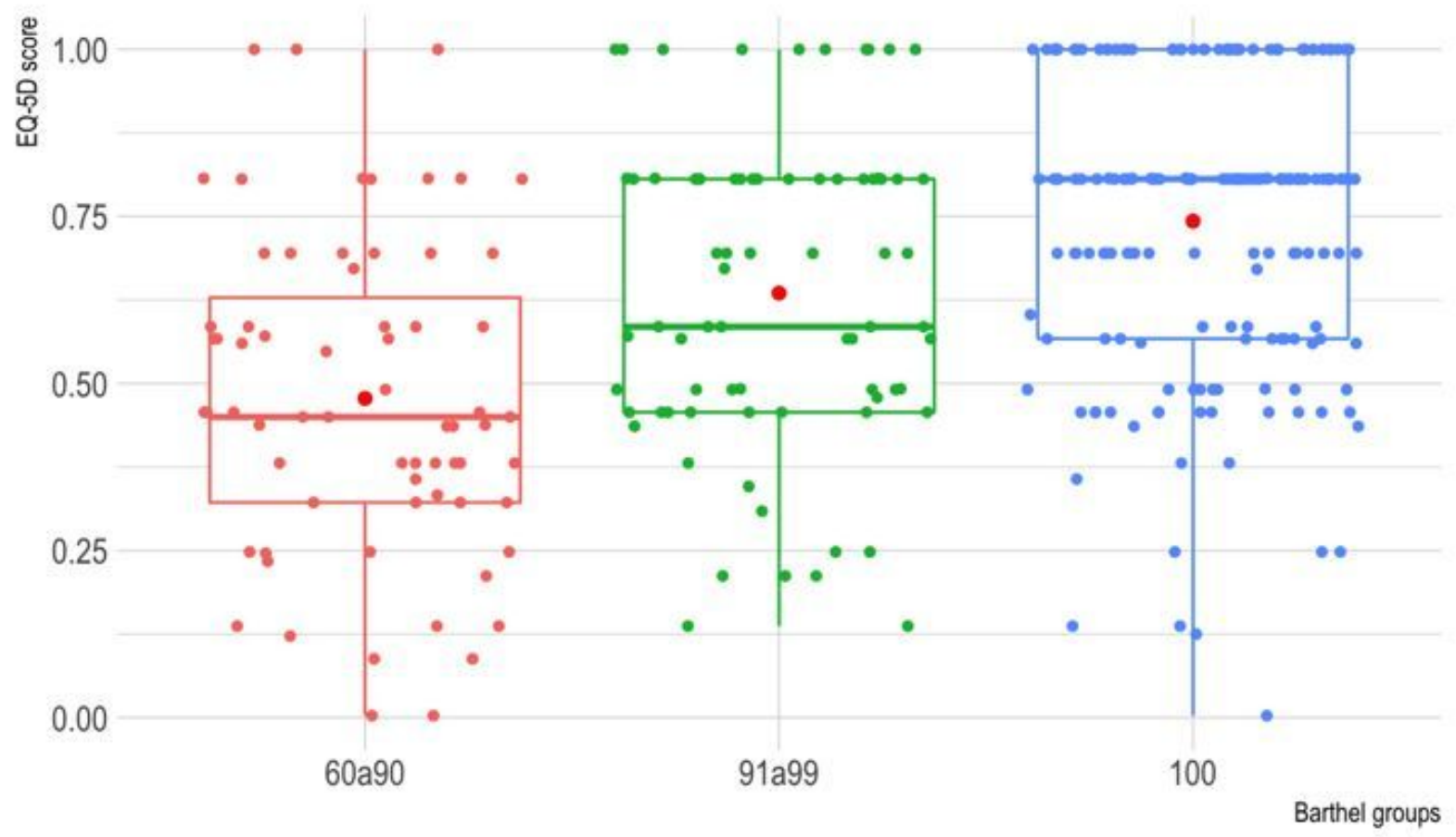

Figure 2

Boxplot of EQ-5D score for the 322 older adults clustered by group of dependency. Note: The red dot in each box represents the mean value for that group.

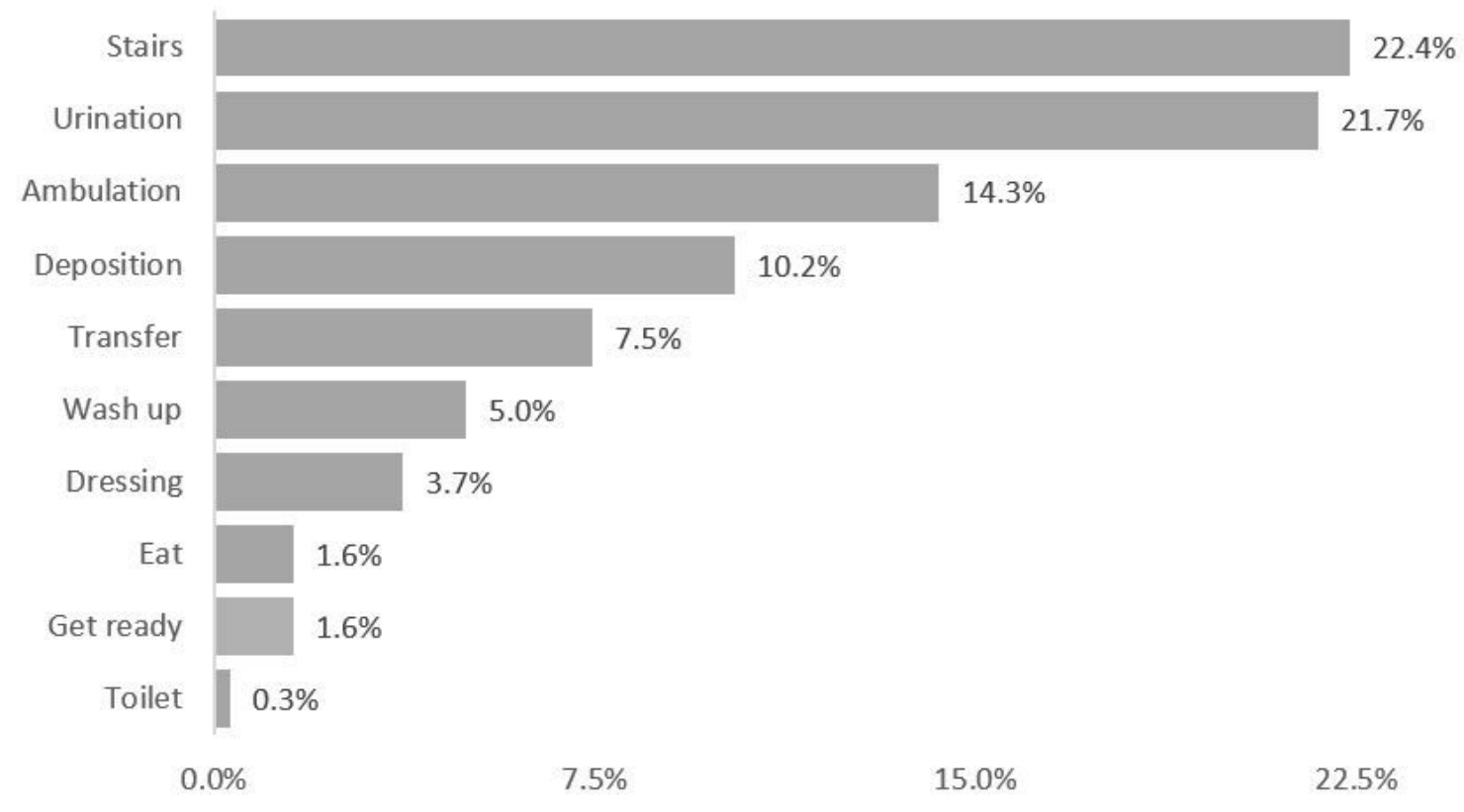

$30.0 \%$

Figure 3 
Percentage of older adults with Barthel Index less than maximum score per activity. Note: (a) Each percentage per activity was calculated by as the number of older adults with a score lower than the maximum score for that activity divided by the 322 older adults. For example, for climbing stairs, 72 out of the 322 older adults scored less than 10 points (max score). (b) ${ }^{\star \star \star}$ test of proportions $p$-value $<0.05$.

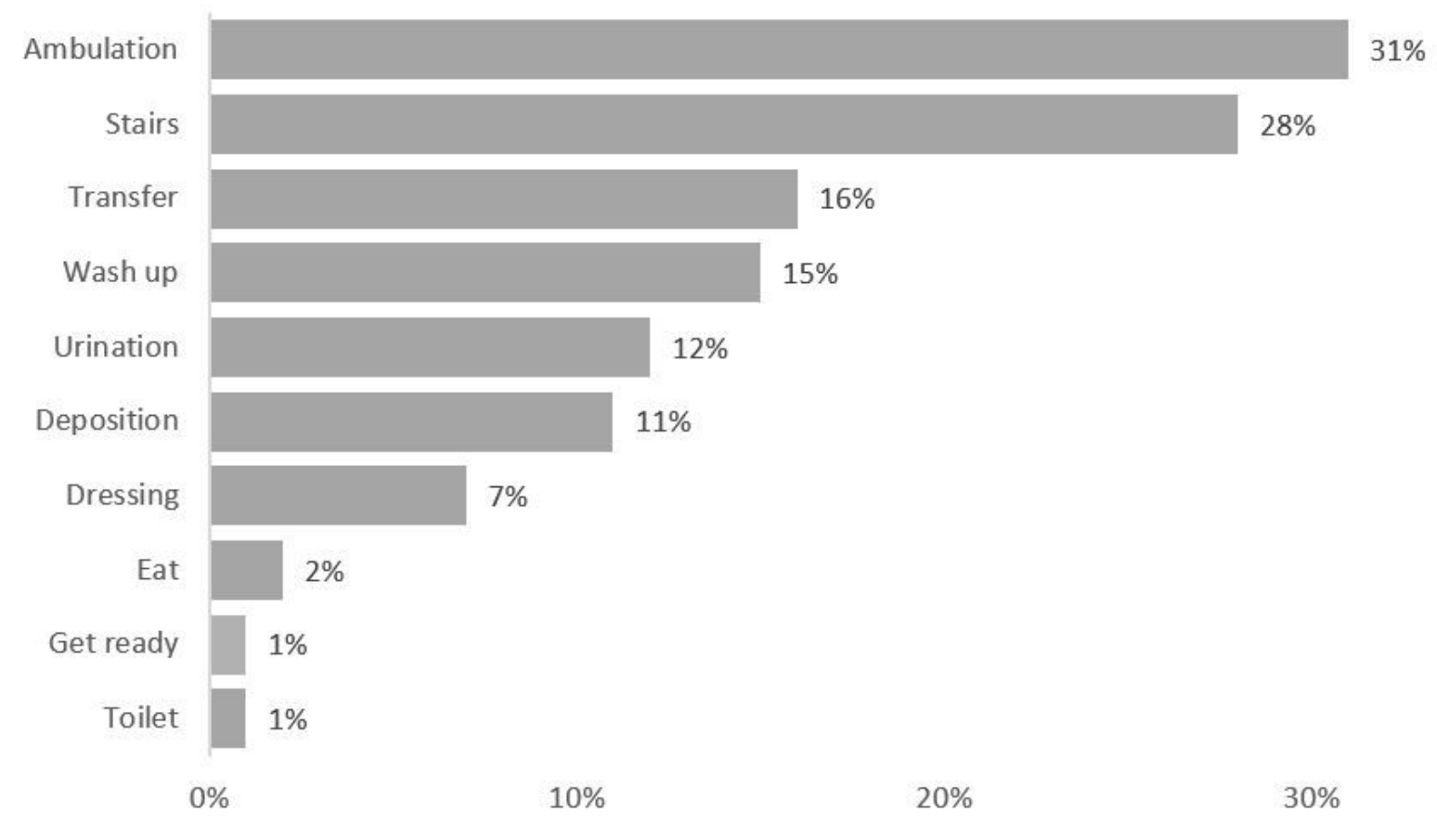

$40 \%$

\section{Figure 4}

Difference between percentage of older adults over and under 0.457 EQ-5D scores by Barthel activity. Notes: (a) The percentage for each activity is calculated taking the difference between the percentage of older adults classified above or below the EQ-5D cutoff score of 0.457 for all older adults classified with maximum score for that activity. For example, for ambulation, $93 \%$ of all older adults with a higher score than 0.457 points in the EQ-5D test scored also the maximum score for ambulation in the Barthel Index, but only $63 \%$ of all older adults with a lower score than 0.457 points in the EQ-5D test scored also the maximum for ambulation in the Barthel Index. The difference of $31 \%$ is reflected in this Figure. (b) ${ }^{\star \star \star}$ test of proportions p-value $<0.05$. 


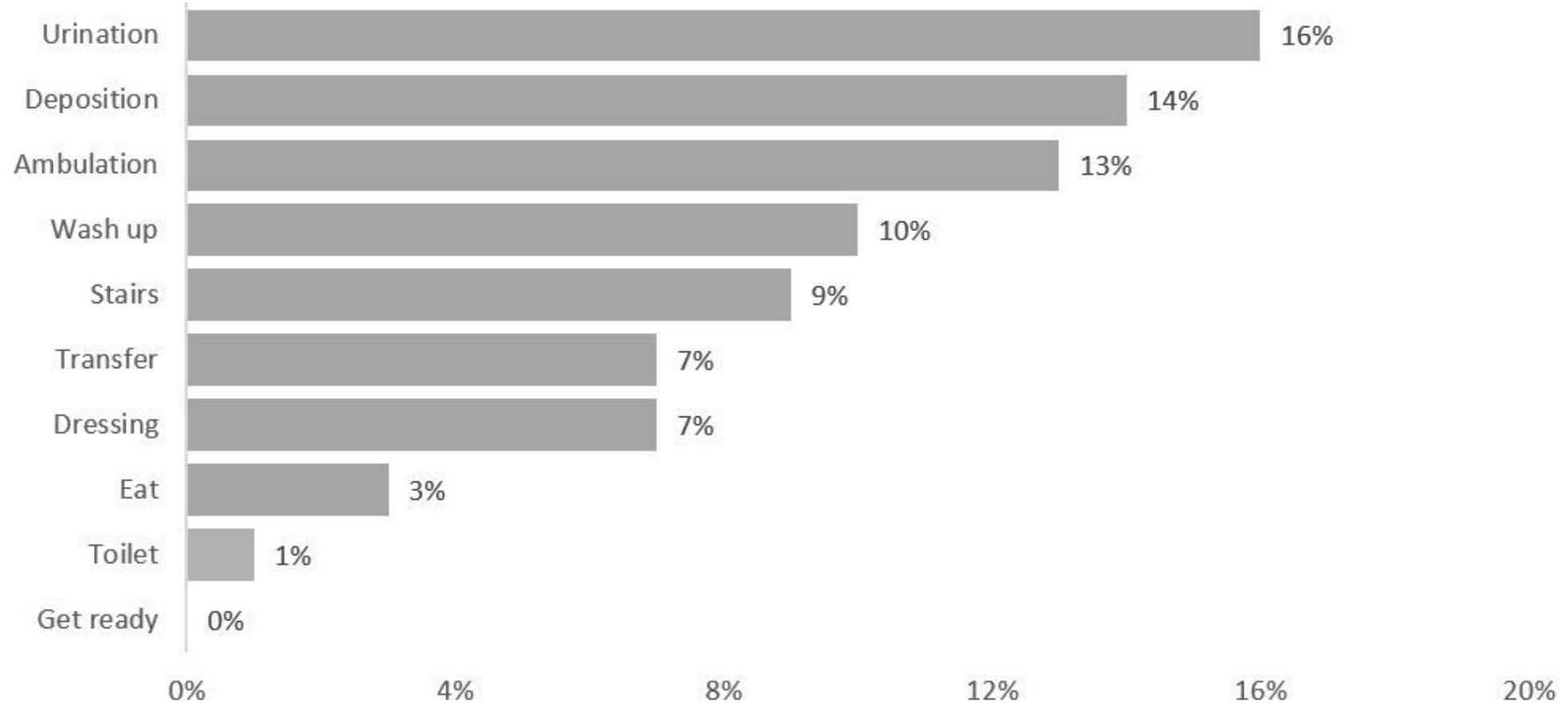

Figure 5

Difference between percentage of older adults over and under 2 points for the Yesavage score by Barthel activity. Note: (a) The percentage for each activity is calculated taking the difference between the percentage of older adults classified above or below the Yesavage cutoff score of normality (score of 2) for all older adults classified with maximum score for that activity. For example, for incontinence of urination $82 \%$ of all older adults with a lower than 2 points in the Yesavage test scored the maximum for incontinence of urination in the Barthel Index, but only $66 \%$ of all older adults with a higher score than 2 points in the Yesavage test scored also the maximum for incontinence of urination in the Barthel Index.

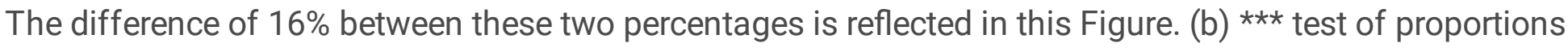
p-value $<0.05$. 